DOMINION OF CANADA-DEPARTMENT OF AGRICULTURE

\title{
MANGE IN HORSES, CATTLE AND SHEEP
}

HEALTH OF ANIMALS DIVISION

A. E. CAMERON, M.C., V.D., V.S.

Veterinary Director General 


\section{MANGE IN HORSES, CATTLE AND SHEEP}

Mange, scabies, or itch is a serious contagious disease of the skin affecting all classes, ages, and conditions of our domestic animals.

It is a scheduled disease under the Animal Contagious Diseases Act.

This Act, and the regulations made thereunder, demand that every owner, breeder, dealer, and veterinary surgeon, suspecting the existence of this disease in horses, cattle, and sheep, shall immediately notify the nearest veterinary inspector.

This action is essential to enable the taking of prompt measures for the control and eradication of outbreaks, with a view to protecting the live stock interests.

Mange is caused by a minute parasite commonly known as a mite, living on, or in the skin, and reproducing itself by means of eggs.

The incubation of these eggs varies according to more or less favourable conditions, dependent upon the season, the activity of the circulation of the animal, and the thickness of the coat.

The symptoms in affected animals vary for these reasons, it not being uncommon for clinically affected animals to apparently recover and later show well marked symptoms.

Under favourable conditions the eggs hatch in from four to seven days, and the young mites develop sufficiently to reproduce themselves in fifteen days.

Authorities have shown that two mites, a male and a female, are capable of producing one million, five hundred thousand $(1,500,000)$ descendants in about three months.

The mite belongs to a very large order of parasite, and is divided into many families, which have distinct characteristics, peculiarities, and preferences.

Some of these families remain on the surface of the skin, and live on the skin debris, and natural excretions of the skin. They conceal themselves under the crusts and scabs, which are produced by their constant irritation.

Other families burrow into the deep layers of the skin, where they form innumerable channels in which they lay their eggs, and hatch out their young.

Although a great deal has been discovered with regard to the life history of the mite it is evident that it has some habits which authorities have so far failed to discover. It has been suggested that the mite may be carried on rats, mice, birds, and various insects, and in this way the disease spread to districts where mange had not previously been detected. It is, however, a well known fact, that this parasite will not remain on the dead animal, as they have been observed directly after the death of their host to swarm off its carcass in innumerable numbers. They very naturally remain in suitable places, until they can obtain access to another animal as they can survive for lengthy periods, especially, if their surroundings are moist. Many of them do eventually get on to an animal, and once upon a new host under favourable conditions, they increase very rapidly, and very soon produce symptoms of the disease. Too much care cannot, therefore, be taken to burn or bury deeply the carcass of any mangy animal.

Certain specific families of mange parasites produce horse mange, others cattle mange, and still again others sheep scab. The disease is not transferable from one species of our domestic animals to another, although a temporary irritation may result following transfers of the mites.

$46.52-1 \frac{1}{2}$ 
The disturbances in the skin caused by the activities of these innumerable mites, and the poisonous secretions which they introduce into the tissue, produce intense itching, accompanied by loss of hair, effusion, thickening of the skin, and the formation of scabs and crusts.

This constant irritation is very injurious to all affected animals, especially so in old or weak animals of low vitality. It results in shrinkage in weight, in unthriftiness, arrested growth, functional disturbance, lowered ritality, and increased death rate.

The discase spreads by contact of mangy animals with healthy ones, and, as the mites can live for various periods off the animal body, healthy animals may also become affected by coming in contact with the materials and places contaminated by mangy stock, such as ropes, halters, harness, saddles, blankets, stables, stable utensils, curry combs, brushes, fences, posts, trees, chutes, stockyards, stock cars; in fact, anything that has been in contact with a mangy animal, and which has not been subsequently disinfected, may be a means of infection.

All cases of mange can be traced to contagion from an existing or pre-existing case.

\section{MANGE OF HORSES}

Mange in horses occurs most frequently in neglected animals; good care and systematic grooming prevent the localization of the parasites, and deter their progress in every way.

Three varieties of mange affect the horse, mule, and ass: Sarcoptic, psoroptic and symbiotic.

The sarcoptic form spreads slowly, but is the most serious, and most difficult form to cure, as the mites bore their way through the outer skin, and burrow underneath it.

The disease at first develops slowly, its specific lesions being seldom noticeable before the expiration of at least three weeks from the date of infection. It is generally first noticed in the region of the withers, whence it extends in an irregular manner over the surface of the body, the extremities usually being left untouched. If neglected it soon produces constitutional disturbance, which, with the loss of rest and food, due to the continual irritation, not unfrequently lead to a fatal termination. Cases of old standing are difficult to treat successfully, the disease frequently reappearing in animals apparently cured. Except in the early stages it is contagious in the extreme. The transmission is generally effected not through the eggs, or the mature egg laving female which are buried in the skin, but through the rapid movements of the younger individuals of both sexes.

Psoroptic mange of the horse, while not so intractable as that produced by the sarcoptes, is still a very serious malady, capable under favourable conditions, of causing great suffering to affected animals, and corresponding loss to the owners. It generally makes its appearance at or near the roots of the mane, or tail. the first indication of infection being the rubbed, or broken appearance of the long hairs of one, or both, of these appendages. Examination will reveal the presence of an eruption of small pimples containing fluid, which on breaking form a crust. This crust, as the exudation continues, becomes thicker but remains moist, thus differing from that of sarcoptic mange which is dry and scaly. As the mites multiply the disease gradually spreads from each centre of infection, and the irritation being greatly increased by constant rubbing, the skin eventually becomes thickened, inflamed and wrinkled, while the hair in many cases either falls out, or is rubbed off. 
Between the wrinkles is to be found a moist, filthy accumulation of broken scab, which, especially in warm weather, is offensive in smell and contributes largely to the general skin irritation.

Symbiotic mange, is, in horses, generally confined to the legs, more especially the hind legs, where it causes great irritation, and eventually loss of hair, thickening and inflammatory exudations. It is most frequently seen in heavy horses with hairy legs. It spreads very slowly and yields readily to treatment. The irritation is much greater in winter than in summer. Affected horses show their discomfort by stamping while in the stable and by rubbing their legs together.

\section{MANGE OF CATTLE}

Four different species of mites affect cattle; psoroptes, sarcoptes, symbiotes, and demodex folliculorum.

The psoroptic form occurs in cattle much more frequently than any of the other varieties, and, although not so troublesome a form as the sarcoptic, causes much greater losses to the cattle industry than the latter.

The mite producing this disease lives upon the surface of the skin, causing irritation and inflammation of the upper layers only, this being a constant and characteristic evidence of the disease. Symptoms of skin irritation are as a rule first seen over the root of the tail, and less frequently over the neck and withers, occasionally extending over the hips, shoulders, back and sides, and in neglected cases it extends over the entire body, with the exception of the lower portion of the legs.

Affected animals show evidence of irritation by persistent licking, rubbing, scratching and switching of the tail. Although the hair conceals the small scabs in the early stages of the disease its disarranged condition over the lesions indicates the parts which should be closely examined.

By manipulating such areas with the hand, dried serum, or scabs, may be found and removed for examination for mites.

As the disease progresses the vesicles and scabs become more numerous and join together. The skin becomes thickened, in the region of the neck, dewlap, and lower portions of the chest, to such an extent as to form folds, the hair falls out, or is rubbed off in patches and the animal loses flesh noticeably.

The diseasc spreads much more quickly among closely confined cattle, and, although it develops much more rapidly, is more severe in its effects on old, weak, or poorly nourished animals. It also has a serious effect upon feed lot animals, as it prevents them from thriving or gaining weight, eren when on full feèd.

One or more attacks of the disease do not confer immunity, and after cattle have been treated and the disease cured, they may become reinfected by contact with infected animals, or by contact with anything contaminated by them.

The sarcoptic form is not frequently seen in cattle. It is, however, a very scrious discase and very difficult to cure. The mites have a tendency to locate on the tender parts of the skin where the hair is short, the lesions being first noticed on the inner surfaces of the thighs, the under side of the neck, or brisket, or around the root of the tail. In neglected cases the disease extends until the entire surface of the body may become involved. The mites burrow into the skin causing inflammation and swelling. Small pimples, or nodules, form on the skin, and discharge serum, which dries and mats the hair, which eventually falls out. As the discase advances, the skin has a dry scurfy, or leatherlike appearance with bald patches, through which scattering hairs remain. When the disease reaches this stage, it rescmbles common scab, and can only be definitely differentiated by the identification of the mite. In the early stages the location and character of the lesions, and the manner of spreading, is sufficient eridence to distinguish it from the psoroptic form. 
Although the sarcoptic form spreads more slowly than common mange, it makes great headway in herds crowded in yards, or stables, where the animals come in close contact.

The symbiotic form occurs occasionally in cattle. It is not a serious disease, as the lesions are limited to the legs and tail. They spread slowly and yield rearlily to treatment.

The demodectic form, commonly known as follicular mange, is not often recognized in cattle. The mites locate only in the hair follicles deep down in the skin. Their activities cause the formation of spherical lumps in the skin, which, upon squeezing, discharge a creamy pus. Owing to the depth of the mites in the skin, this disease is practically incurable, although its progress may be delayed by regular dipping in a suitable mixture.

\section{MANGE OF SHEEP, SHEEP SCAB}

Three forms of mange affect sheep, the sarcoptic, psoroptic and symbiotic forms.

This disease is even more serious in sheep than in horses or cattle; it is not only injurious to the health of the sheep, but it depreciates, very materially, the value of the wool.

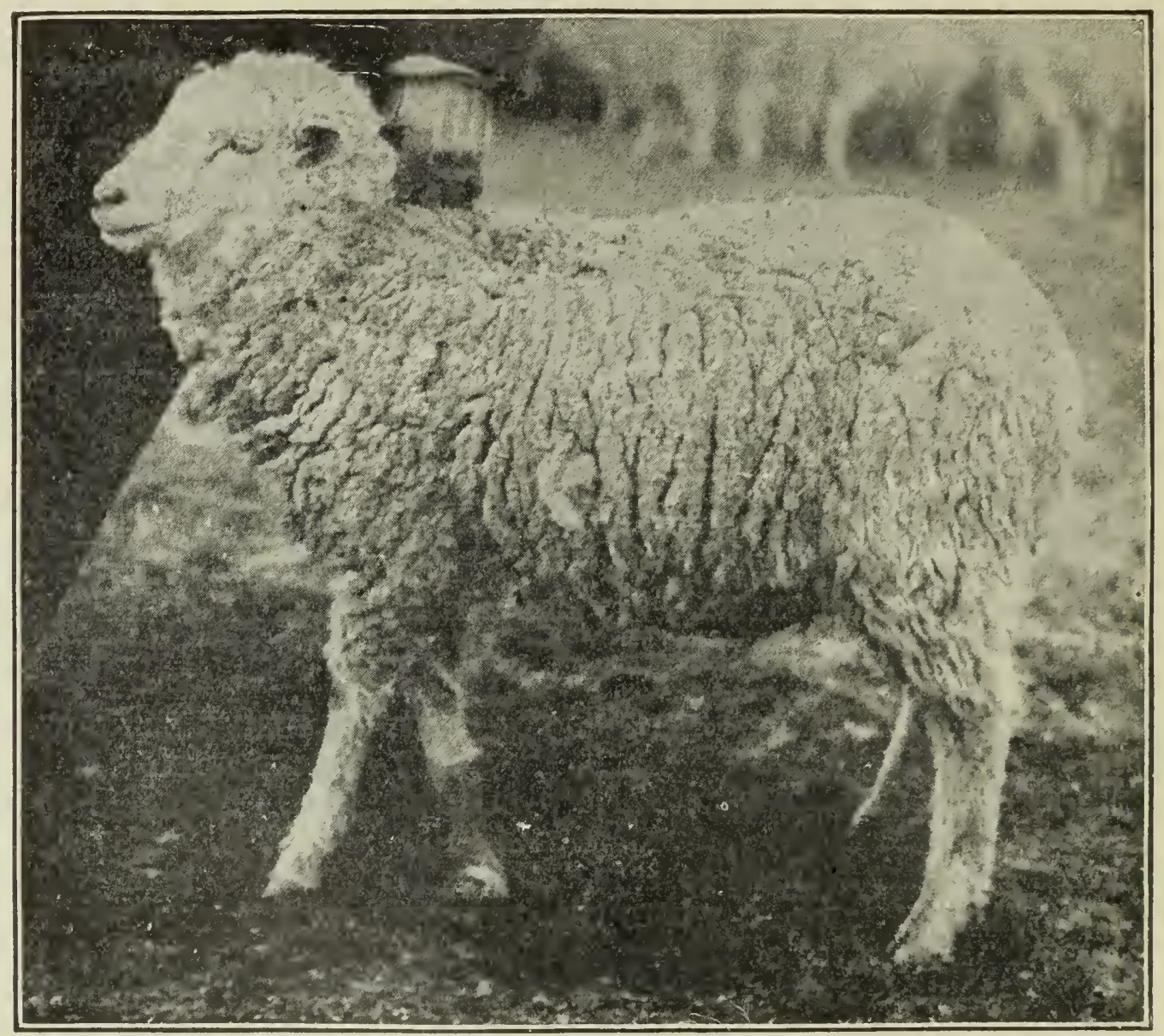

Sheep Scab

It is a difficult disease to control, and eradicate, as sheep are herded in large flocks, and are almost continually in direct contact with each other. This continual close contact affords excellent facilities for the spread of infection. The wool also furnishes ideal shelter and warmth for the mites.

The psoroptic form is the true scab of sheep, and is by far the most common. These mites, unlike those of the sarcoptic rariety, attack the parts of 
the body, which are thickly covered with wool, and as they are well protected, with sufficient warmth, they increase very rapidly, unless proper measures are taken to suppress them.

The mites first attack the upper and middle part of the body, the withers, and back, and then the neck, flanks, and the croup. Itching is the first symptom noticed. The affected animals rub, scratch, and bite the intensely irritable parts, often tearing out the wool, which gives their coats a ruffled appearance.

As the discase progresses, papules form on the skin. These increase rapidly in number, and soon become confluent. The papules exude serum, and develop into vesicles and pustules, the skin thickens, and crusts form as the exudation from the resicles and pustules dry.

The affected surfaces are soon covered with a yellowish, scaly, gluey layer, and as the animal endeavours to allay the itching by every possible means, the wool is torn and pulled out in patches. The crusts fall off and are replaced by others, which are thicker, more compact and non-adherent. The lesions become intensified, and a dry crust-like parchment soon covers the tumefied skin.

The fleece very quickly shows a characteristic neglected appearance; the wool being matted in some parts, and entircly absent in others. In patches where the wool is still adhering to the body, it is loose and easily pulled out.

The sarcoptic form is not very serious in sheep as the mites only attack the parts of the body which are not covered with wool. This disease is easily controlled and eradicated by proper treatment and careful disinfection of all contact material, but, unless this action is taken the disease may perpetuate itself indefinitely.

The first lesions noticed are generally on the face, commencing near the lips, and extending orer the face to the head, and in some instances to the outside surface of the ears.

In specially severe cases the lesions have been noted on the back of the knees, hocks, and under the belly.

Symptoms of intense itching are soon apparent, denoted by the animals scratching, and rubbing their heads constantly, and violently against the feed racks, and other objects. Vesicles appear, which upon being injured by rubbing or scratching, discharge a serum. This dries and soon hard nodules form, adhering closely to the skin.

As the discase progresses crusts and scabs form over the nodules, and eventually join together. The skin quickly thickens and forms folds, which soon crack and bleed through injury by rubbing.

The symbiotic form of mange, or scab, is not serious, and is not very contagious as it spreads only to a small percentage of a flock. The mites attack the lower parts of the limbs and cause severe irritation. This disedse is, howcrer, easily controlled and eradicated.

\section{TREATMENT OF MANGE}

This being a reportable discase, its suspected existence must be promptly reported to the nearest reterinary inspector.

As the symptoms and skin lesions are the result of the activities of the mite. treatment must be directed to their destruction, both on the animal body, and on all contact material. It is, therefore, necessary to apply to the bodies of affected, and exposed animals, a mixture which will destroy the mites, and also to disinfect thoroughly and effectively all places and materials with which affected animals have been in contact. Suitable mixtures, which destroy the mites, do not destroy the eggs, and ronsecpuently it is essential to apply treat- 
ment at definite intervals in oreter to kill the young mites before they are capable of laying eggs: As the eggs hatch in from four to seven days, and the young mites do not lay eggs until they are fifteen days old, a period of not less than twelve, nor more than fourteen days must be allower to lapse between each dipping.

Animals should be clipped (if at all practicable) before treatment, but this procedure is selfom possible, when dealing with large numbers of affected horses and cattle; it is, however, essential in the treatment of scabby sheep. In order to protect animals from reinfection, all contact matter should be rarefully and effectively disinfected promptly afte" cach treatment; too great care cannot be exercised in this connection.

Treatment consists of either hand applications or the immersion of the animals in suitable dipping vats. The first method can only be employed in outbreaks comprising a limited number of gentle tractable animals. To obtain the best results in horses and cattle. the animals should first be clipped, all crusts and scabs removed by washing with hot water and castile soap, and the remedy applied as soon as the animal's roat is dry. The following mixture is used officially for hand treatment for hores and cattle, and must be applied under the supervision of a veterinary inspector. It is not suitable for the treatment of sheep.

Sulphur, 2 pounds.

Oil of tar, 8 ounces.

Raw linseed oil, 1 gallon.

'These ingredients should be gradually heated together', but not boiled. as the sulphur and tar will cake on the bottom of the vessel if heated too rapidly and if brought to the boiling point. This dressing should be very thoroughly applied over the whole surface of the body and extremities of the animal, including the cars and tail, at a temperature not less than 110 degrees F., and not more than 120 degrees $\mathrm{F}$.

Two dressings are necessary. Forty-eight hours before the second application (twelfth to fourteenth day inclusive) the first dressing should be washed off with hot water and castile soap. Ten days after the second application the animals should again be washed to remove the dressing.

If the mixture has been properly prepared and very thoroughly applied the two treatments should effect a cure in ordinary cases, but in severe cases it may be necessary to apply the treatment many times.

Upon completion of the first treatment all refuse must be promptly burned, and all places and materials with which the animals have been in contact must be thoroughly disinfected.

Only such disinfectants as are registered under the Pest Control Products Act should be used. Full instructions for the mixing of disinfectants are given on Health of Animals Form 62, which can be procured free of charge by application to the Veterinary Director General at Ottawa.

In outbreaks comprising a large number of animals dipping in a lime and sulphur mixture has given satisfactory results.

This mixture consists of:-

Flowers of sulphur, 24 pounds.

Fresh unslaked lime. 10 pounds.

Water, 100 gallons.

The preparation of this mixture is of the greatest importance. The lime should be carefully slaked, and made into a paste, the sulphur then added, and thoroughly incorporated with the paste; the whole added to sufficient water 
preferably boiling water, and thoroughly boiled for at least two hours, and while boiling must be frequently stirred. The mixture should then be of a rich brown or chocolate colour. Allow mixture to stand for a few hours, better still over night, then drain off liquid but do not disturb sediment, and add sufficient water to make one hundred gallons. The vat is filled with the mixture in the above proportions, and heated to not less than 110 degrees $\mathrm{F}$. nor more than 115 degrees $\mathrm{F}$.

This temperature must be maintained while the animals are held in the vat for at least two minutes. During this period all crusts and scabs must be loosened with a stiff brush. This procedure is most important, in order to enable the mixture to come in contact with the mites under these scabs and crusts. Upon completion of first dip all refuse must be promptly burned, and all infected places and materials thoroughly disinfected.

The second dipping must be undertaken between the twelfth and fourteenth day after the first dip, in order to destroy the new generation of mites before they mature.

There are two varieties of dipping vats, the cage and the swimming. The cage vat gives excellent results and is preferable to the swimming vat, but its use is not practicable when a large number of animals are to be dipped.

The symptoms of mange are so easily recognized that no owner, or stockman can be excused for not reporting on the plea of ignorance. The intense itching causes the animals to bite at their bodies, scratch and rub incessantly against any object, and the skin quickly thickens; it is soon covered with scabs and crusts followed by loss of hair or wool.

Under proper treatment and strict sanitation the disease is curable but if neglected may necessitate the slaughter of badly diseased animals.

\section{ACKNOWLEDGMENT}

The illustrations used in this Bulletin were obtained through the courtesy of Dr. Jno. R. Mohler, Chief of the Bureau of Animal Industry, Washington, D.C., U.S.A. 

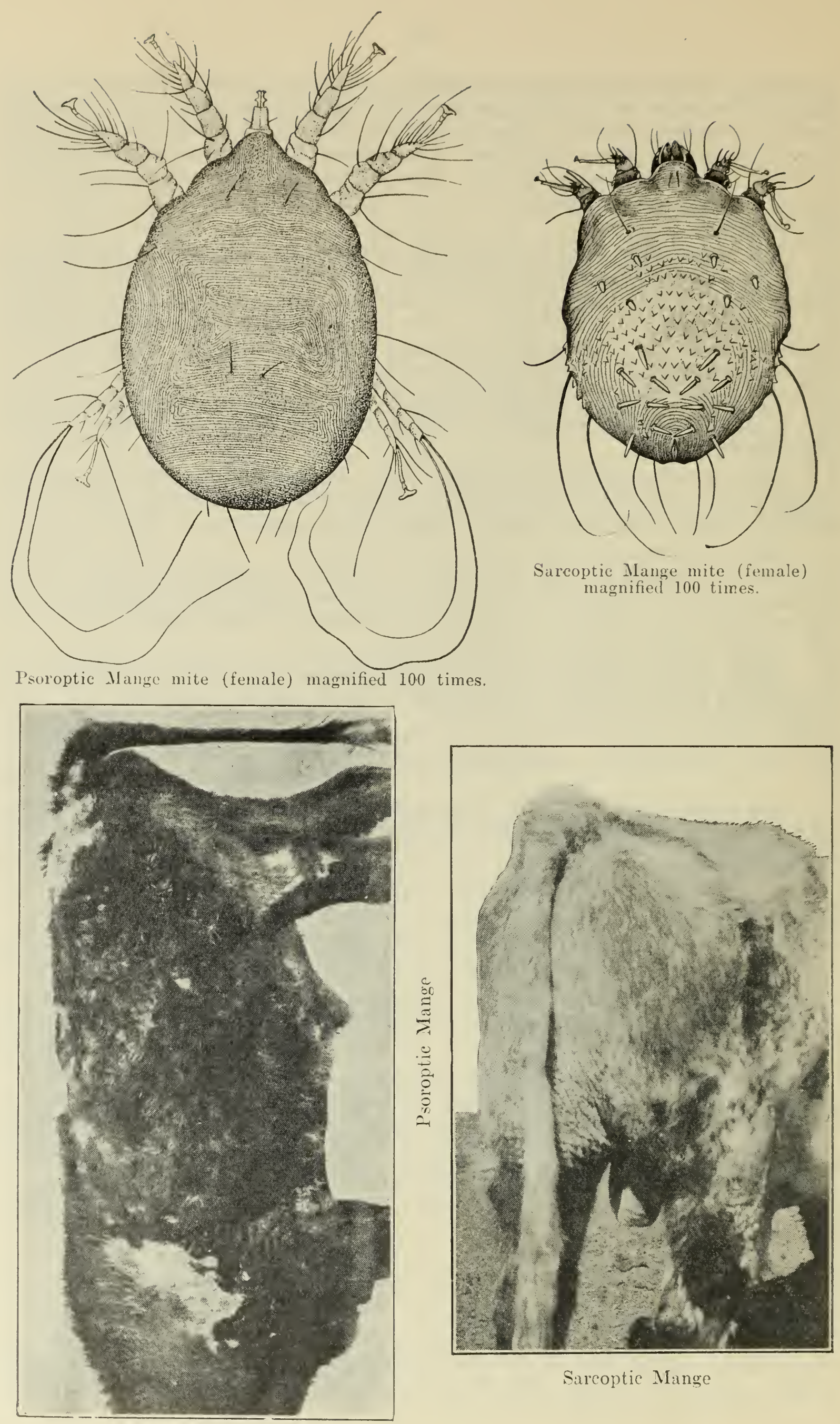

Sarcoptic Mange 


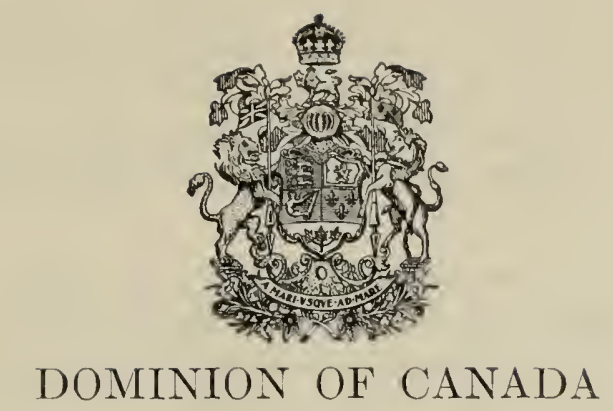

\section{REGULATIONS RELATING TO MANGE}

By Order in Council dated 22nd July, 1911, in virtue of "The Animal Contagious Diseases Act, R.S.C., 1927"

1. No animal which is affected with or has been exposed to the infection of mange shall be permitted to run at large or to come in contact with any animal not so affected or exposed.

2. Any inspector may declare to be an infected place within the meaning of the "Animal Contagious Diseases Act," any place or premises where the infection of mange is known or suspected to exist.

3. No animal nor any portion or product thereof shall be removed out of any place so declared to be an infected place without a licence signed by an inspector.

4. Inspectors are hereby authorized to inspect any animals affected with mange, or suspected of being so affected, or which have been in contact with animals so affected, or suspected of being so affected, or which have been in any way whatever exposed to the infection of mange, and may order any such animals to be collected, detained, isolated, dipped, or otherwise dealt with, as may to them appear advisable.

5. The expenses of, and incidental to the collection, isolation, seizure, or otherwise dealing with animals for the purposes of these Regulations shall be borne by the owners of the animals and no indemnity shall be allowed to the owner in case of damage arising out of, or resulting from such actions except as hereinafter provided.

6. Where a veterinary inspector so orders, no animal or animals shall be allowed access to any field, common, yard, stable, or other place or premises where mange exists or has existed.

7. The premises on which animals affected with mange have been kept are to be dealt with at the expense of the owner in a manner satisfactory to the veterinary inspector.

8. Animals affected with mange or which have been in contact with, or in close proximity to animals affected with mange, may, on an order signed by a veterinary inspector, duly appointed under the "Animal Contagious Diseascs Act," be forthwith slaughtered and the carcasses disposed of as in such order prescribed, compensation to be paid to the owners of such animals if and when the Act so provides, but no inspector shall order the slaughter of such animals without having first received, from the minister, special authority to do so.

9. Before an order is made for the payment of compensation in any of the cases aforesaid there must be produced to the Minister of Agriculture a satisfactory report, order for slaughter, certificate of valuation and slaughter, and certificate of cleansing and disinfection, all signed by an inspector. 
10. Any inspector may declare any steamship, stcam, or other reszel, railway ear or other vehicle, on or in which animals affected with or suspected of being affected with mange are or have been placed for the purpose of transit, to be infected, and may also declare such vessel, car or other vehicle, to be no longer infected after it has been thoroughly reansed and disinfected in accordance with his instructions.

11. Wvery yard, stable, cowshed, outhouse, or other place or premises, and every wagon, cart, carriage, car, or other vehicle, and every utensil or other thing infected of suspected of being infected with mange shall be thoroughly cleansed and disinfected by, and at the expense of the owner or occupier in a manner satisfactory to an inspector.

Healith of Animals Division,

Departuent of Agriculture,

OTTAWA. 


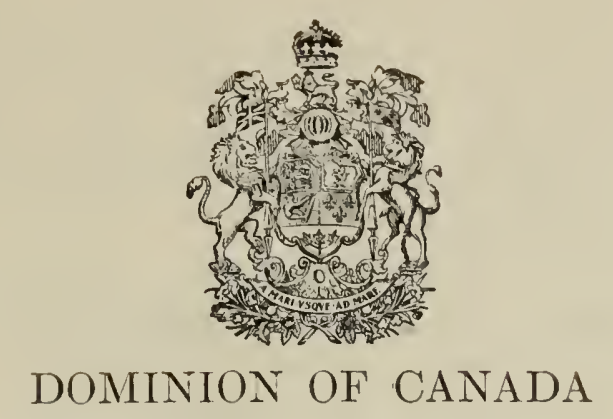

REgULATIONS RELATING TO SHEEP SCAB

By Order in Council dated 22nd July, 1911, in virtue of "The Animal Contagious
Diseases Act, R.S.C., 192" "

1. No sheep which is affected with, or has been exposed to the infection of sheep scab shall be permitted to run at large or to come in contact with any animal not so affected or exposed.

2. Any inspector may declare to be an infected place within the meaning of "The Animal Contagious Diseases Act," any place or premises where the infection of sheep scab is known or suspected to exist.

3. No sheep nor any wool or other portion or product thereof shall be removed out of any place so declared to be an infected place without a licence signed by an inspector.

4. Inspectors are hereby authorized to inspect any sheep affected with sheep scab, or suspected of being so affected, or which have been in contact with animals so affected, or suspected of being so affected or which have been in any way whatever exposed to the infection of sheep scab, and may order any such animals to be collected, detained, isolated, dipped or otherwise dealt with as may to them appear advisable.

5. The expenses of, and incidental to the collection, isolation, seizure, or otherwise dealing with animals for the purposes of these Regulations shall be borne by the owners of the animals and no indemnity shall be allowed to the owner in case of damages arising out of or resulting from such actions except as hereinafter provided.

6. Where a veterinary inspector so orders, no sheep shall be allowed access to any field, common, yard, stable, or other place or premises where sheep scab exists or has existed.

7. Premises on which animals affected with sheep scab have been kept, are to be dealt with at the expense of the owner or occupier in a manner satisfactory to the veterinary inspector.

8. Animals affected with sheep scab or which have becn in contact with or in close proximity to animals affected with sheep scab, may, on an order signed by a veterinary inspector, duly appointed under the Animal Contagious Diseases Act, be forthwith slaughtered and the carcasses disposed of as in such order prescribed, compensation to be paid to the owners of such animals if and when the Act so provides, but no inspector shall order the slaughter of such animals without having first received from the minister special authority to do so.

9. Before an order is made for the payment of compensation in any of che cases aforesaid, there must be produced to the Minister of Agriculture a satisfactory report, order for slaughter, certificate of valuation and slaughter, and certificate of cleansing and disinfection, all signed by an inspector. 
10. Any inspector may declare any steamship, steam or other vessel, railway car or other vehicle, on or in which animals afferted with or suspected of being affecter with sleep scab, are, or have been placed for the purpose. of transit, to be infected, and may also declare such vessel, car or other vehicle, to be no longer infected after it has been thoroughly cleansed and disinfected in accordance with his instructions.

11. Every yard, stable, cowshed, outhouse, or other place or premises, and every wagon, cart, carriage, car, or other vehicle, and every utensil or other thing infected or suspected of being infected with sheep scab shall be thoroughly cleansed and disinfected by and at the expense of the owner or occupier in a manner satisfactory to an inspector.

Health or Animals Division,

Departaent of Agriculture,

OtTaWA. 

